OPEN ACCESS

Edited by:

Antônio Teixeira Do Amaral,

State University of the North

Fluminense Darcy Ribeiro, Brazil

Reviewed by:

Vesna Dragicevic,

Maize Research Institute Zemun

Polje, Serbia

Alireza Pour-Aboughadareh,

Seed and Plant Improvement

Institute, Iran

*Correspondence:

J. Lydia Pramitha

lydiapramitha@gmail.com

Specialty section:

This article was submitted to

Plant Breeding,

a section of the journal

Frontiers in Plant Science

Received: 22 September 2021

Accepted: 16 December 2021

Published: 19 January 2022

Citation:

Lydia Pramitha J, Joel J, Rajasekaran R, Uma D, Vinothana K, Balakrishnan M, Sathyasheela KRV, Muthurajan R and Hossain F (2022)

Stability Analysis and Heterotic

Studies in Maize (Zea mays L.) Inbreds to Develop Hybrids With Low Phytic Acid and High-Quality Protein. Front. Plant Sci. 12:781469. doi: 10.3389/fp/s.2021.781469

\section{Stability Analysis and Heterotic Studies in Maize (Zea mays L.) Inbreds to Develop Hybrids With Low Phytic Acid and High-Quality Protein}

\author{
J. Lydia Pramitha ${ }^{1,2 *}$, John Joel ${ }^{1}$, Ravikesavan Rajasekaran ${ }^{1}$, D. Uma ${ }^{1}$, \\ Kumari Vinothana ${ }^{1}$, Meenakumari Balakrishnan ${ }^{1}$, K. R. V. Sathyasheela ${ }^{1}$, \\ Raveendran Muthurajan ${ }^{1}$ and Firoz Hossain ${ }^{1,3}$
}

${ }^{1}$ Tamil Nadu Agricultural University, Coimbatore, India, ${ }^{2}$ School of Agriculture and Biosciences, Karunya Institute of Technology and Sciences, Coimbatore, India, ${ }^{3}$ Division of Genetics, Indian Agricultural Research Institute, New Delhi, India

Maize is a major staple crop with high value as food and feed in the poultry sector. Considering the overall nutritional value, maize-based diets comprise two major constraints, i.e., higher phytic acid (PA) and lack of tryptophan. To overcome these issues, a set of identified stable donors for low PA (Ipa) and higher tryptophan were crossed in a line $\times$ tester fashion, and the hybrids obtained were evaluated at three locations with two replications. Among the inbreds for yield, UMI 1201 and UMI 1205 were the stable good combiners, and for PA, UMI 447 and LPA-2-285 were identified as efficient combiners across locations. Subsequently, 72 hybrids developed from these inbreds had a reduced phytate and higher tryptophan compared with checks having alterations in their yield levels. From Additive Main Effects and Multiplicative Interaction (AMMI) and Genotype main effect plus genotype-by-environment interaction (GGE) biplots, DMRQPM-09-13-1 × UMl 1099 (PA:9.38 mg/g, trp:0.06\%, and yield:184.35 g) and UMl 1205 $\times$ UMI 467 (PA:7.04 mg/g, trp:0.06\%, and yield:166.39 g) were stable for their high yield with medium PA and tryptophan. Also, across environments, UMl $1200 \times$ UMl 467 had a stable average yield of $129.91 \mathrm{~g}$ along with the lowest PA of $4.50 \mathrm{mg} / \mathrm{g}$ and higher tryptophan of $0.07 \%$. Thus, these hybrids could be selected and evaluated in upcoming biofortification trials to benefit the poultry sector. Furthermore, the parental inbreds utilized were grouped into heterotic pools to serve as a source population for the development of Ipa hybrids in future programs.

Keywords: Ipa (low phytic acid), tryptophan, combining ability, AMMI, GGE biplot, heterotic grouping

\section{INTRODUCTION}

Maize is a $\mathrm{C}_{4}$ cereal that serves as a major staple food and feeds for poultry as well as swine due to its easier availability, palatability, and nutritional emolument (Shah Rouf et al., 2016). It is rich in carbohydrates, vitamins, minerals, proteins, and trace elements such as selenium and magnesium (Farnham et al., 2003). Although it has a higher nutritional value, the presence of phytic acid (PA) and the lack of tryptophan in its zein have been an issue in ascertaining the bioavailability of nutrients and proteins in maize diets (Naidoo et al., 2012). The higher PA in maize hinders 
nutrient absorption in monogastric animals due to its polyanionic nature and causes the chelation of positively charged mineral cations such as iron and zinc (Raboy et al., 2001). Unlike plants, the nonruminants lack the enzyme phytase for dissolution, and this PA complex from maize feeds thus obstructs mineral absorption.

An alternative approach to resolve this is by supplementing artificial fungal phytase in poultry feeds increased the feed cost rather than enhancing the micronutrient bioavailability (Lelis et al., 2012). Hence, developing low PA (lpa) lines would offer a possible solution to mineral absorption in maize-based foods. Speaking of nutrition, another subsequent lacuna in maize zein is the absence of tryptophan, and it is an essential amino acid with numerous regulatory functions (Vasal, 2000). The solution to this was effected by incorporating opaque- 2 with its genetic modifiers in the endosperm (Ignjatovic-Micic et al., 2014). However, this remains incomplete without manipulating the PA in maize for efficient absorption of minerals to achieve overall nutritional value. Hence, combining lpa and higher tryptophan in breeding programs will overcome the prime nutritional lacuna faced in maize-based foods. Furthermore, these improved hybrids would eventually increase the body mass ratio and nutrient uptake in chicks with a simultaneous cutdown of additional chemical supplements in diets (Lelis et al., 2012).

In addition, these nutritional improvisations should also be accompanied by increased yield for their commercialization, and this reinstates the utilization of heterosis in maize by hybridizing the identified donors with elite lines (Sureshkumar et al., 2014). Hybrid development for cultivation necessitates its stable performance as PA and tryptophan in maize are reported to vary across locations (Zaidi et al., 2008; Brankovic et al., 2016). Hence, identifying stable hybrids with uniform genotype and environment $(G \times E)$ interactions by effective models such as Additive Main Effects and Multiplicative Interaction (AMMI) and Genotype main effect plus genotype-by-environment interaction (GGE) biplot enhances the selection for these traits in breeding trials. These numerical and graphical approaches in stability are predominantly used to discriminate the genotypes for response variable and mega environments graphically thereby locating stable lines in crop improvement programs (Akhtar et al., 2018; Vaezi et al., 2019).
Speaking of both lpa and tryptophan in a hybrid, this is an initial program aimed to produce a high-yielding stable maize hybrid with a desirable lower PA and higher tryptophan content. Therefore, this could be used as a base to formulate the upcoming integrated breeding approaches in maize. In this study, a set of 17 inbreds identified as potential donors for lpa and higher tryptophan from our previous findings (Pramitha et al., 2020b) were hybridized in a line $\times$ tester mating design, and the resultant hybrids were raised across diverse locations for analyzing its stability. To further dissect its genetic and molecular backgrounds, these stable parental inbreds have been grouped in heterotic pools to facilitate the production of high-performing hybrid combinations with superior nutritional parameters in near future.

\section{MATERIALS AND METHODS}

The stable inbreds were selected from the framed germplasm reference set in maize (Pramitha et al., 2020a). This included eight inbreds for $l p a$, six for higher tryptophan, and three for yield. They were obtained from the Department of Millets, TNAU, and were intercrossed in a line $\times$ tester fashion. The six inbreds for tryptophan and three high-yielding lines were used as females, with eight $l p a$ inbreds as male (Table 1). The resultant 72 hybrids with two agronomically superior checks, namely, $\mathrm{CO} 6$ and $\mathrm{COH}$ (M) 8, were raised at three locations, namely, $\mathrm{E}_{1}$ : Coimbatore, $\mathrm{E}_{2}$ : Vagarai, and $\mathrm{E}_{3}$ : Bhavanisagar (Table 2). The parents and the hybrids were evaluated in a randomized block design with two replications in each location (Pramitha et al., 2020b).

Both hybrids and parental lines were screened for 20 morphological traits, namely, days to $50 \%$ tasseling, days to $50 \%$ silking, anthesis silking interval, plant height, tassel length, number of tassel branches, cob placement height, cob length, cob girth, number of rows per cob, number of kernels per row, cob weight, shank weight, shelling percentage, 100 seed weight, seed length, seed girth, seed thickness, single plant yield, and seedling vigor index (Abdul-Baki and Anderson, 1973); and for four biochemical traits, namely, PA (Davies and Reid, 1979), inorganic phosphorus (Raboy, 2000), starch (Clegg, 1956), and tryptophan (Galicia et al., 2009). Finally, the iron and zinc of the selected stable hybrids with checks were also analyzed (Palmer and Piper, 1966).

TABLE 1 | The parental inbreds (female lines and male testers) used in the study.

\begin{tabular}{|c|c|c|c|c|c|c|c|}
\hline S.No & Lines & Code & Days to maturity & S.No & Testers (Ipa inbreds) & Code & Days to maturity \\
\hline 1. & UMI 1200 & L1 & 117.00 & 1. & LPA-2-285 & $\mathrm{T} 1$ & 111.67 \\
\hline 2. & UMI 1201 & L2 & 119.83 & 2. & LPA-2-395 & T2 & 118.50 \\
\hline 4. & DMR-QPM-01-06-02 & L4 & 117.00 & 4. & UMI 467 & T4 & 118.00 \\
\hline 5. & DMR-QPM-03-72 & L5 & 115.50 & 5. & UMI 158 & T5 & 115.17 \\
\hline 8. & DMR-QPM-09-13-1 & L8 & 117.67 & 8. & UMI 113 & T8 & 117.67 \\
\hline 9. & DMR-QPM-11-17 & L9 & 114.67 & & & & \\
\hline
\end{tabular}


TABLE 2 | Description of the three locations in stability.

\begin{tabular}{llllll}
\hline S.No & Location & Latitude & Longitude & Soil type & Annual rainfall \\
\hline 1. & Coimbatore & $11.00^{\circ} \mathrm{N}$ & $76.98^{\circ} \mathrm{N}$ & Red loamy & $827 \mathrm{~mm}$ \\
2. & Bhavanisagar & $11.46^{\circ} \mathrm{N}$ & $77.10^{\circ} \mathrm{N}$ & Sandy loam soil & $717 \mathrm{~mm}$ \\
3. & Vagarai & $10.58^{\circ} \mathrm{N}$ & $77.56^{\circ} \mathrm{N}$ & Black soil & $600 \mathrm{~mm}$ \\
\hline
\end{tabular}

\section{Biochemical Estimation}

The standard protocols for the five nutritional traits are furnished below.

\section{Phytic Acid}

A finely ground whole grain maize sample $(0.5 \mathrm{~g})$ was taken from each genotype and continuously stirred for $3 \mathrm{~h}$ with $10 \mathrm{ml}$ of $0.5 \mathrm{M} \mathrm{HNO}_{3}$. The sample was then filtered via Whatman No. 1 paper, and $200 \mu \mathrm{l}$ of the aliquot was transferred to Eppendorf tubes having $200 \mu \mathrm{l}$ of freshly prepared ferrous ammonium sulfate $(2.16 \mathrm{mg} / \mathrm{ml})$. These tubes were shaken and incubated in a boiling water bath for $20 \mathrm{~min}$. Following this, the tubes were cooled, and $1 \mathrm{ml}$ of isoamyl alcohol and $20 \mu \mathrm{l}$ of ammonium thiocyanate $(5 \mathrm{~g} / 50 \mathrm{ml})$ were added. The tubes were shaken well and then centrifuged at 3,000 rpm for $10 \mathrm{~min}$. The color developed was read at $460 \mathrm{~nm}$, and it was spectrophotometrically analyzed in two replicates with sodium phytate as a standard (Davies and Reid, 1979).

\section{High Inorganic Phosphorous (HIP) Assay}

The grounded whole maize kernel samples of $0.1 \mathrm{~g}$ were soaked overnight in $0.4 \mathrm{M} \mathrm{HCl}$. The next day after shaking, $100 \mu \mathrm{l}$ of the extract was separately taken in another tube, and $900 \mu \mathrm{l}$ of freshly prepared Chen's reagent $\left(6 \mathrm{~N} \mathrm{H}_{2} \mathrm{SO}_{4}: 2.5 \%\right.$ ammonium molybdate: $10 \%$ ascorbic acid: $\mathrm{H}_{2} \mathrm{O}$ [1:1:1:2, v/v/v/v]) was added. The developed phosphomolybdate complex after an incubation of $30 \mathrm{~min}$ was read at $660 \mathrm{~nm}$ in a spectrophotometer with two replications having serial dilutions of potassium dihydrogen phosphate as a standard (Raboy, 2000).

\section{Starch}

Two grams of powdered whole grain samples were homogenized with $80 \%$ ethanol and centrifuged at $12,000 \mathrm{rpm}$ for $15 \mathrm{~min}$. This centrifugation was repeated until the washings of the supernatant with anthrone were colorless. When a colorless washing with anthrone was obtained, the supernatant was discarded, and the residue was well dried in a hot water bath. After drying, $5 \mathrm{ml}$ of water and $6.5 \mathrm{ml}$ of $52 \%$ perchloric acid were added and incubated for $20 \mathrm{~min}$ at $0^{\circ} \mathrm{C}$. The supernatant was then transferred to a volumetric flask, and again, the extraction with $52 \%$ perchloric acid and water was repeated. This second supernatant was also added to the same volumetric flask, and the volume was made up to $100 \mathrm{ml}$ with water. Notably, $0.1 \mathrm{ml}$ of the pooled extracts were taken and made up to $1 \mathrm{ml}$ with water. To this, $4 \mathrm{ml}$ of anthrone $(200 \mathrm{mg}$ in $5 \mathrm{ml}$ distilled ethanol made up to $100 \mathrm{ml}$ with ice-cold $95 \%$ sulfuric acid) was added and kept in a hot water bath. The color developed was read at $630 \mathrm{~nm}$ in two replications in a spectrophotometer, and glucose was used as a standard (Clegg, 1956).

\section{Tryptophan}

Two grams of powdered whole grain samples were placed in a filter paper envelope and were defatted in a soxhlet apparatus with hexane for $3 \mathrm{~h}$. Notably, $80 \mathrm{mg}$ of the defatted powder was added in a falcon tube with $3 \mathrm{ml}$ of papain solution $40 \mathrm{mg}$ of papain dissolved in $0.165 \mathrm{~N}$ of sodium acetate ( $\mathrm{pH}: 7.5)$. These tubes were vortexed and kept in a hot air oven at $64^{\circ} \mathrm{C}$ for $16 \mathrm{~h}$. After cooling, the tubes were centrifuged at 3,600 rpm for $5 \mathrm{~min}$, and $1 \mathrm{ml}$ of hydrolysate was added to another tube containing $3 \mathrm{ml}$ of freshly prepared reagent D $(20 \mathrm{ml}$ of $1.8 \mathrm{mM}$ ferric chloride prepared in $100 \mathrm{ml}$ of glyoxylic acid stock $(0.9025 \mathrm{~g}$ of glyoxylic acid in $100 \mathrm{ml}$ conical flask is added with $50 \mathrm{ml}$ of $7 \mathrm{~N} \mathrm{H}_{2} \mathrm{SO}_{4}$ and made up to $100 \mathrm{ml}$ ) $+20 \mathrm{ml}$ of $30 \mathrm{~N} \mathrm{H}_{2} \mathrm{SO}_{4}$ ) was vortexed. This was further incubated at $64^{\circ} \mathrm{C}$ for $30 \mathrm{~min}$, and the tubes after cooling were read at $560 \mathrm{~nm}$ in two replications with a series of tryptophan (Galicia et al., 2009) as standards in the spectrophotometer.

\section{Iron and Zinc}

To $0.5 \mathrm{~g}$ of whole grain maize samples, $10 \mathrm{ml}$ of a triacid mixture (9 $\mathrm{ml}$ nitric acid: $2 \mathrm{ml}$ sulfuric acid: $1 \mathrm{ml}$ perchloric acid) was added and allowed for digestion at room temperature overnight. On the following day, another digestion of these samples was carried out in a hot sand bath until the digest was clear and colorless. After cooling, the contents were diluted to $50 \mathrm{ml}$ with double distilled water, and the Fe and $\mathrm{Zn}$ (Palmer and Piper, 1966) were read at 248.33 and $213.86 \mathrm{~nm}$, respectively, in an atomic absorption spectrophotometer.

\section{Statistical Analysis}

The combining ability analysis (Kempthorne, 1957) and the standard heterosis (Meredith and Bridge, 1972) with a high yielding check CO 6 were estimated in the statistical package of TNAUSTAT. The pooled ANOVA, including AMMI and GGE biplot for stability given by Gauch (1992), was analyzed in R studio 3.6.2 and PBTools 1.4 (Pramitha et al., 2020b). The classification of inbreds based on their combining ability in heterotic pools was carried out based on the diverse general combining ability ( $g c a)$ effects adopted by Legesse et al. (2009).

\section{RESULTS AND DISCUSSION}

The main focus of this study was to overcome the major nutritional stern in maize, and it was successful with the efficient donors for lpa and tryptophan (Pramitha et al., 2020b). This is the initial research framed to combine these two traits in hybridization, and the observations of this study could be used in other integrated programs of maize. Maize is well known for its heterotic expression from the eras of Shull (1909), and in this, the expression of a phenotype across locations has revealed the importance of attributing traits beneath a response factor. The phenotypic expression of a genotype depends on the $\mathrm{G} \times \mathrm{E}$ interaction. In addition, several contributing traits and genes over locations here have influenced the ability to transfer the favorable 
alleles in a cross for complex characters (Ferreira et al., 2018; Murtadha et al., 2018).

Due to this, the per se and combining ability of a parent in a crossing program is important, and it confers the ability to allocate favorable genes in a hybrid (Fasahat, 2016). Thus, this study across locations enables us to understand the variations in mean, combining ability effects and heterotic potential among the parental inbreds and hybrids for yield,

TABLE 3 | ANOVA for combining ability across locations.

\begin{tabular}{|c|c|c|c|c|c|c|}
\hline SOURCE & REP & CROSS & LINE & TESTER & LINE $\times$ TESTER & ERROR \\
\hline $50 \mathrm{DT}^{\star}$ & 0.174 & $10.102^{\star \star}$ & $21.804^{\star \star}$ & $13.213^{\star \star}$ & $8.042^{\star \star}$ & 0.089 \\
\hline ASI & 0.050 & $0.874^{\star \star}$ & $1.460^{\star \star}$ & $0.441^{\star \star}$ & $0.845^{\star \star}$ & 0.059 \\
\hline $\mathrm{CPH}$ & 0.293 & $196.478^{\star \star}$ & $296.569^{\star \star}$ & $479.531^{\star \star}$ & $146.798^{\star \star}$ & 5.037 \\
\hline TBR & 0.499 & $5.817^{\star \star}$ & $7.980^{\star \star}$ & $6.545^{\star \star}$ & $5.417^{\star \star}$ & 0.307 \\
\hline $\mathrm{CL}$ & 0.246 & $1.892^{\star \star}$ & $2.920^{\star \star}$ & $3.211^{\star \star}$ & $1.580^{\star \star}$ & 0.208 \\
\hline$C G$ & 0.004 & $0.974^{\star *}$ & $1.730^{\star \star}$ & $3.408^{\star \star}$ & $0.561^{\star \star}$ & 0.128 \\
\hline $\mathrm{NKr} / \mathrm{R}$ & 0.418 & $15.774^{\star \star}$ & $33.714^{\star \star}$ & $14.309^{* \star}$ & $13.394^{\star \star}$ & 0.325 \\
\hline $\mathrm{NR} / \mathrm{C}$ & 0.015 & $1.302^{\star \star}$ & $2.221^{\star \star}$ & $1.829^{\star \star}$ & $1.105^{\star \star}$ & 0.078 \\
\hline $100 \mathrm{SW}$ & 0.057 & $25.554^{\star \star}$ & $74.081^{\star \star}$ & $85.264^{\star \star}$ & $11.157^{\star \star}$ & 0.113 \\
\hline SL & 0.001 & $0.008^{\star \star}$ & $0.006^{\star \star}$ & $0.033^{\star \star}$ & $0.005^{\star \star}$ & 0.001 \\
\hline$S G$ & 0.002 & $0.010^{* *}$ & $0.014^{* *}$ & $0.036^{* \star}$ & $0.007^{\star \star}$ & 0.0001 \\
\hline ST & 0.000 & $0.003^{\star \star}$ & $0.005^{\star \star}$ & $0.005^{\star \star}$ & $0.002^{\star \star}$ & 0.0001 \\
\hline SVI & $39,724.556$ & $832,227.331^{\star *}$ & $1,769,444.016^{\star \star}$ & $1,169,860.154^{\star \star}$ & $656,135.131^{\star \star}$ & $9,410.735$ \\
\hline STR & 1.136 & $34.601^{\star \star}$ & $53.559^{\star \star}$ & $65.108^{\star \star}$ & $28.080^{\star \star}$ & 0.533 \\
\hline HIP & 0.002 & $0.062^{\star \star}$ & $0.058^{\star \star}$ & $0.040^{\star \star}$ & $0.065^{\star \star}$ & 0.002 \\
\hline TRP & 0.001 & $0.001^{\star \star}$ & $0.001^{\star \star}$ & $0.001^{\star \star}$ & $0.001^{\star \star}$ & 0.0001 \\
\hline PA & 0.008 & $3.330^{\star *}$ & $2.837^{\star \star}$ & $4.838^{\star \star}$ & $3.212^{\star *}$ & 0.030 \\
\hline
\end{tabular}

50 DT, days to 50\% tasseling; 50 DS, days to 50\% silking; ASI, anthesis silking interval; CPH, cob placement height, PH, plant height; TL, tassel length; TBR, number of the tassel of branches; $C L$, cob length; CG, cob girth; Nkr/R, number of kernels per row; NR/C, number of rows per cob, CW, cob weight; SHW, shank weight; SH\%, shelling percentage; SPY, single plant yield; 100 SW, hundred seed weight; SL, seed length; SG, seed girth; ST, seed thickness; SVI, seedling vigor index; STR, starch content; HIP, high inorganic phosphorus; TRP, tryptophan; PA, phytic acid. *significant at 5\%; **significant at $1 \%$.

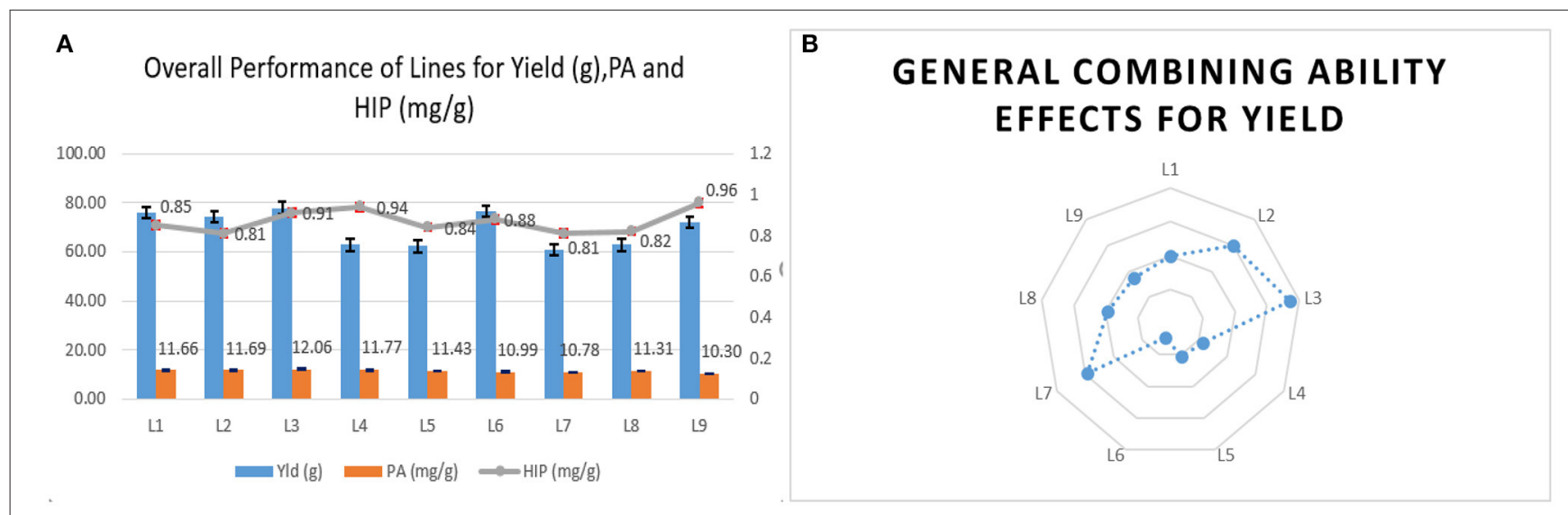

FIGURE 1 | The general mean performance and combining ability of female lines. (A) The overall mean performance of the female lines for single plant yield (g), phytic acid (PA), and high inorganic phosphorus (HIP) in $\mathrm{mg} / \mathrm{g}$. (B) The overall performance of the female lines in a series of crosses (gca) is depicted. 
PA, and tryptophan. The ANOVA for pooled combining ability analysis revealed a significant variation for lines and testers (Table 3). Accordingly, these varying genotypes and their cross combinations were evaluated at three locations to identify stable parents and hybrids for improved yield, tryptophan, and lpa (Lahane et al., 2014; Kumar et al., 2016). The selected desirable hybrids from each location were finally subjected to stability analysis to identify an ideal hybrid for further evaluation.

\section{Identification of Elite Parents Across Locations}

The female parents selected for the study were found agronomically superior to the lpa testers for yield. Among lines, the mean and general combining ability was positively significant in UMI 1201 for 15 yield contributing traits in location $\mathrm{E}_{1}$ and 10 traits in $\mathrm{E}_{2}$. Although UMI 1201 had a higher mean performance for yield in $E_{1}$, UMI 1205 surpassed this in $E_{2}$ with a better performance in 16 attributing traits. In $E_{3}$, there were similar performances for yield in UMI 1205.
Following this, UMI 1201 had a high nonsignificant yield with a significant gca effect. Hence, among the lines, UMI 1205 and UMI 1201 were observed to perform better with a higher mean cum $g c a$ effects across locations (Figures 1A,B). Including yield, these inbreds had higher per se cum gca effects for cob weight, cob placement height, 100 seed weight, and starch content (Supplementary Material). These attributing traits were observed to be stable and higher in these inbreds, and this states their contribution toward the potential combining ability across locations (Al-Naggar et al., 2016; Kuselan, 2017). Hence, UMI 1205 and UMI 1201 could be used as female lines for producing elite hybrids in maize (Lahane et al., 2014; Kumar et al., 2016).

The identified tryptophan donors were used as lines, and among them, DMR-QPM-04-05 and DMR-QPM-01-06-2 had significant positive gca effects for tryptophan in $E_{1}$ and $E_{3}$. Although DMR-QPM-01-06-02 in $\mathrm{E}_{1}$ had a higher mean for tryptophan, in $\mathrm{E}_{2}$, it failed to exhibit a significant mean. Across locations, it is observed that DMR-QPM-04-05 had a positive significant mean and $g c a$ for tryptophan. The significant $g c a$

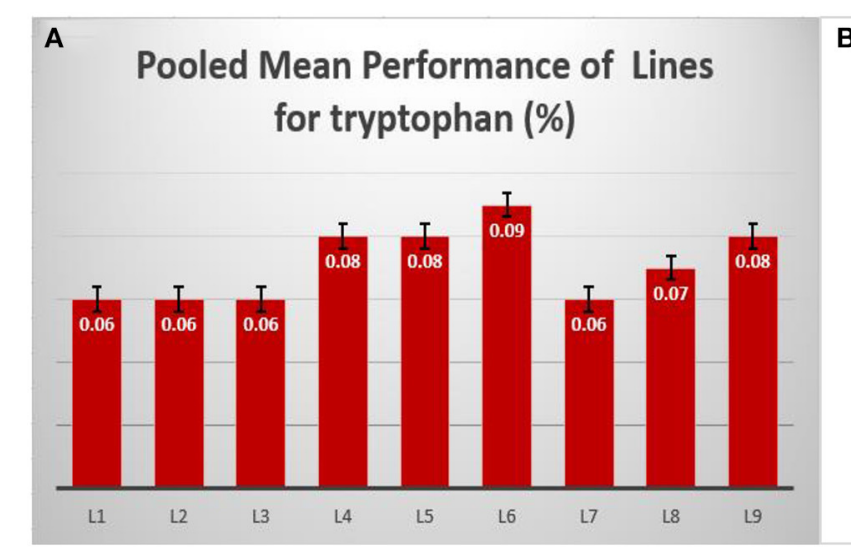

B

\section{GENERAL COMBINING ABILITY EFFECTS FOR TRYPTOPHAN}

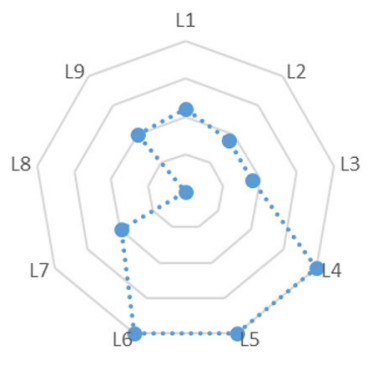

FIGURE 2 | The overall pooled mean performance and general combining ability of female lines for tryptophan. (A) The pooled mean performance of lines for tryptophan content. (B) The general performance of lines in a series of crosses for tryptophan.

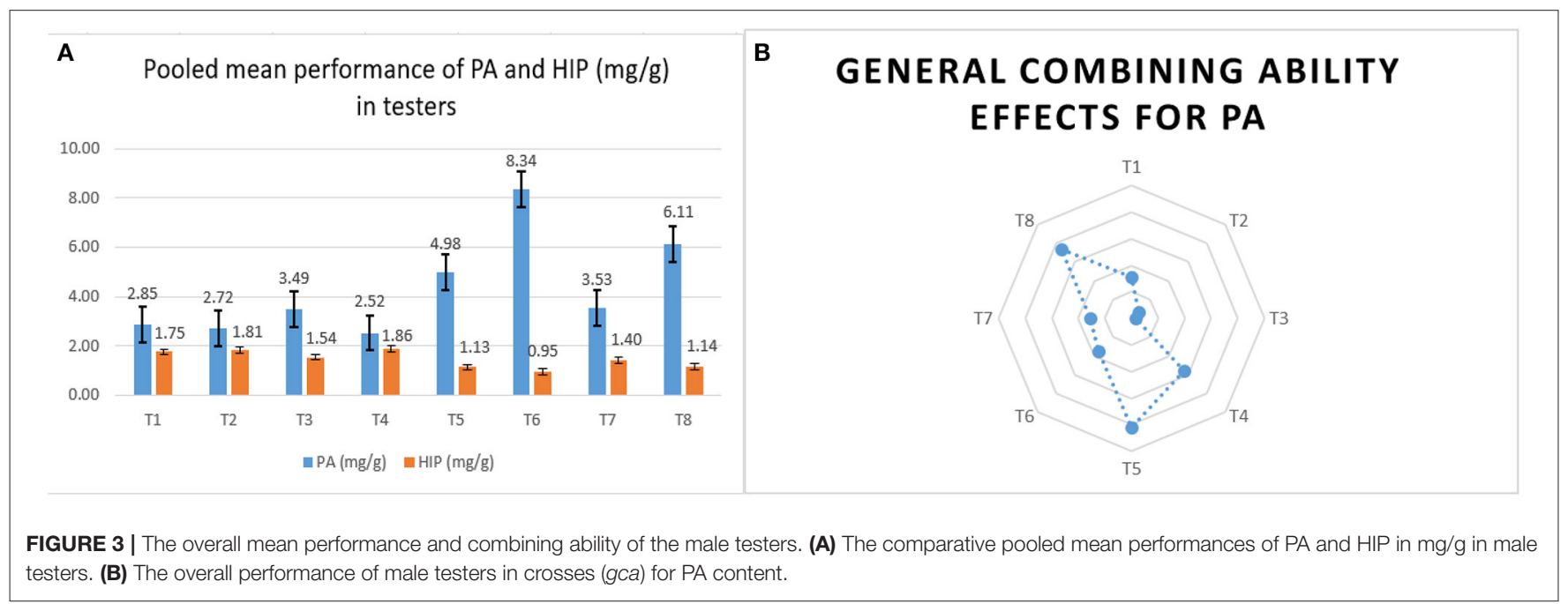


of this inbred across locations describes a higher heritability with less environmental influence for tryptophan (Fasahat, 2016). Hence, this line could be used as an efficient donor for tryptophan (Figures 2A,B).

The stable donors for lpa as testers had a lower phytate. The negative $g c a$ effect for PA in them is a positive indication for developing lpa hybrids, as they eventually reduce the PA content in a series of cross combinations. Among the eight testers, LPA-2-285, UMI 447, and UMI 467 had significantly lower mean and negative gca effects for $\mathrm{PA}$ in $\mathrm{E}_{1}$ and $E_{3}$. In $E_{2}$, except for UMI 467, the other lines had a negative gca for PA. Although UMI 467 was stable in lower mean performance, its reliability as a parent in reducing the phytate in hybrids by negative significant gca was not evident in $\mathrm{E}_{2}$. Hence, LPA-2-285 and UMI 447 could be used as stable potential low phytate combiners in hybridization programs (Lahane et al., 2014).

The tester, UMI 467, had the lowest PA (2.52 mg/g) and HIP $(1.86 \mathrm{mg} / \mathrm{g}$ ) across locations, but it failed to reinstate its utility as a $l p a$ parent in hybridization due to its positive gca in $\mathrm{E}_{2}$. Hence, UMI 467 could be used in introgression programs for developing an elite $l p a$ inbred in maize. Similar findings of these parental inbreds were also reported earlier by Chandana et al. (2018) and Vengilat et al. (2019). On the whole, among the parents, the testers had a lower starch and average growth attribute than the lines due to the reduction in $\mathrm{PA}$ as reported by Sparvoli and Eleonora (2015). Therefore, these pleiotropic effects in lpa lines have to be manifested for developing elite hybrids in the future (Figures 3A,B).

\section{Best Performing Single Cross Hybrids Over Locations}

The ratio of GCA/SCA variance was lesser than unity for all traits across locations (Table 3), and this presented the preponderance of nonadditive gene action for hybrid vigor, which is observed in all the traits over locations (Malik et al., 2004; Mural, 2012; Ferreira et al., 2018). Among all the hybrids evaluated in $\mathrm{E}_{1}$, $\mathrm{E}_{2}$, and $\mathrm{E}_{3}$, DMR-QPM-09-13-1 $\times$ UMI 1099 recorded the highest yield and specific combining ability (sca) effect. Following this, DMR-QPM-06-12 × LPA-2-285, UMI $1205 \times$ UMI 467, DMR-QPM-01-06-02 × K-155, and UMI $1201 \times$ LPA-2-285 had a significantly higher yield and $s c a$ effects for yield in $\mathrm{E}_{1}$.

TABLE 4 | ANOVA for pooled analysis of hybrids for yield and phytic acid (PA).

\begin{tabular}{llcc} 
Source & df & Phytic acid & Single plant yield \\
\hline Environment & 2 & $6.373133^{\star \star}$ & $2362.574^{\star \star}$ \\
Replication (Environment) & 3 & 0.08075 & $13.05783^{\star}$ \\
Genotypes & 73 & $13.22204^{\star *}$ & $3,112.771^{\star \star}$ \\
Environment $\times$ Genotype & 146 & $3.545372^{\star *}$ & $686.1868^{\star *}$ \\
Residuals & 219 & 0.159932 & 16.42773
\end{tabular}

*significant at 5\%; ** significant at $1 \%$.
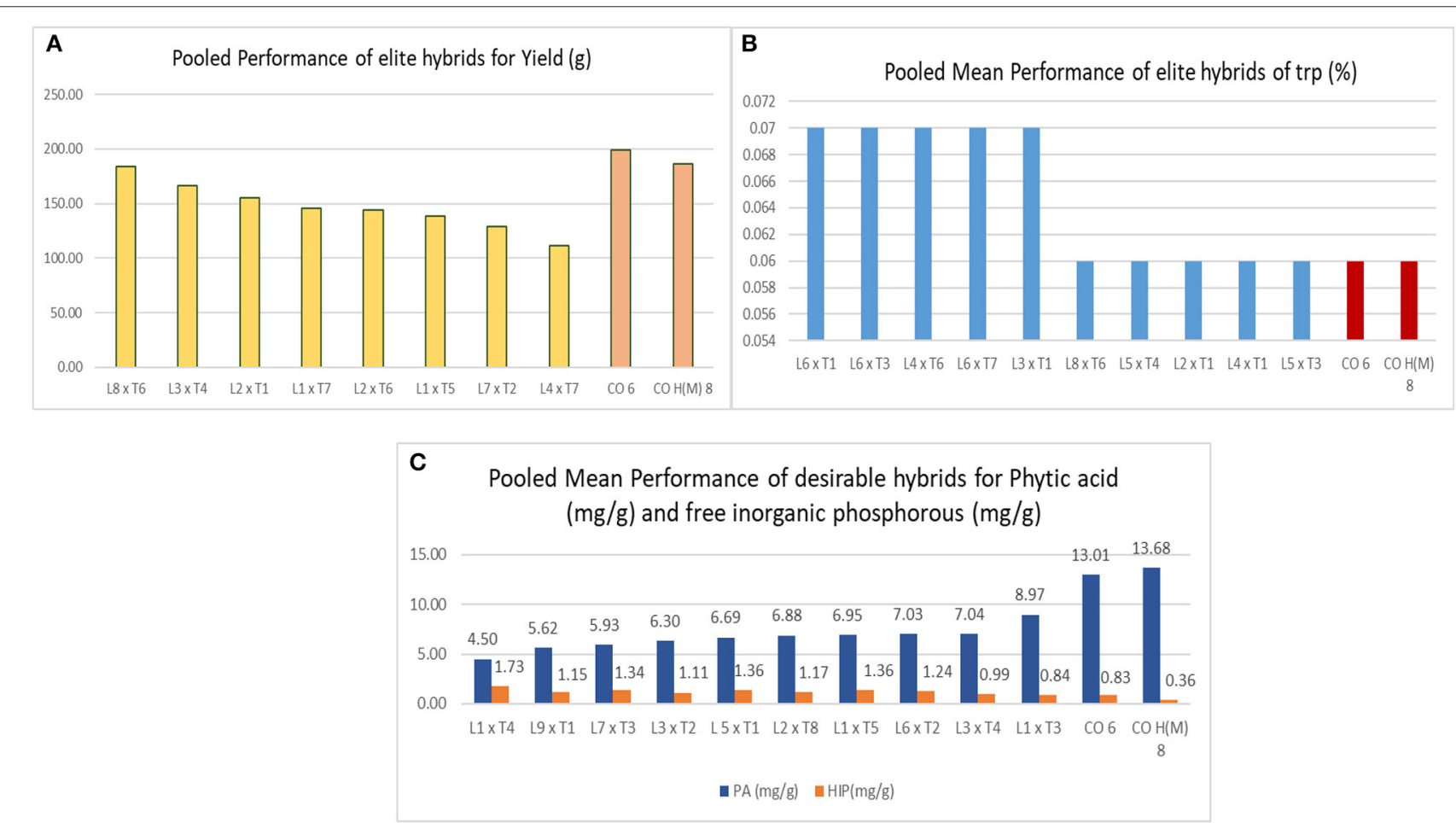

FIGURE 4 | Depicts the top hybrids for the response factors, such as single plant yield, tryptophan, PA, and HIP. (A) The top hybrids for yield among all locations with checks highlighted in orange. (B) The top hybrids for tryptophan content across locations. and (C) the top hybrids with low PA and HIP (mg/g). 
The top yielders with significant $s c a$ effects in $\mathrm{E}_{2}$ after DMRQPM-09-13-1 $\times$ UMI 1099 had slight variations from $E_{1}$, and they were DMR-QPM-06-12 $\times$ LPA-2-285, UMI $1201 \times$ LPA2-285, UMI $1205 \times$ UMI 467, and UMI $1200 \times$ UMI 158 . Similarly, in $E_{3}$, the successive yielders and superior hybrids were DMR-QPM-06-12 × LPA-2-285, UMI $1205 \times$ UMI 467, UMI $1200 \times \mathrm{K}-155$, and UMI $1201 \times$ UMI 1099. Hence, it is clear that DMR-QPM-09-13-1 $\times$ UMI 1099 followed by DMRQPM-06-12 $\times$ LPA-2-285 recorded the highest mean and sca effect in all the environments for yield. Therefore, regarding the performance of the hybrids for yield, DMR-QPM-09-13-1 $\times$ UMI 1099, DMR-QPM-06-12 × LPA-2-285, UMI $1205 \times$ UMI 467, UMI $1201 \times$ LPA-2-285, DMR-QPM-01-06-02 $\times$ K155 , UMI $1200 \times \mathrm{K}-155$, UMI $1200 \times \mathrm{UMI} 158$, and UMI $1201 \times$ UMI 1099 were elite in individual locations and were forwarded to stability models for identifying an ideal hybrid (Figure 4A).
The tryptophan content in hybrids was higher than checks, but none of them had a similar higher performance in other locations as observed for yield. The crosses DMR-QPM04-05 × LPA-2-285, DMR-QPM-04-05 × UMI 447, DMRQPM-09-13-1 × UMI 1099, DMR-QPM-01-06-02 × UMI 1099, and DMR-QPM-03-72 $\times$ UMI 467 in $\mathrm{E}_{1}$, UMI 1201 $\times$ LPA-2-285, DMR-QPM-01-06-02 $\times$ LPA-2-285, and DMRQPM-03-72 $\times$ UMI 447 in $\mathrm{E}_{2}$, and DMR-QPM-04-05 $\times \mathrm{K}$ 155 and UMI $1205 \times$ LPA-2-285 in E3 recorded a higher tryptophan (0.09\%) with a poor yield (Lorenz et al., 2008). Thus, all these hybrids were subjected to a stability model for identifying a stable lpa hybrid with higher tryptophan in them (Figure 4B).

Considering the lpa here, all the hybrids had a significantly lower PA than the checks, and among them, UMI $1200 \times$ UMI 467 exhibited a lower phytate with negative $s c a$ in $\mathrm{E}_{2}$ and $\mathrm{E}_{3}$. In $\mathrm{E}_{1}$, the lowest PA was observed in DMR-QPM-11-17 $\times$

TABLE 5 | The codes for the selected hybrids subjected to AMMI and GGE.

\begin{tabular}{|c|c|c|c|c|c|}
\hline S.No & Codes & Hybrids & S.No & Codes & Hybrids \\
\hline 2 & $\mathrm{H} 2$ & UMl $1200 \times$ UMl 447 & 15 & $\mathrm{H} 15$ & DMR-QPM-06-12 × UMI 447 \\
\hline 4 & $\mathrm{H} 4$ & UMl $1200 \times$ UMl 158 & 17 & $\mathrm{H} 17$ & DMR-QPM-11-17 × LPA-2-285 \\
\hline 5 & $\mathrm{H} 5$ & UMI $1200 \times \mathrm{K}-155$ & 18 & $\mathrm{C} 1$ & CO 6 \\
\hline 8 & $\mathrm{H} 8$ & UMI $1201 \times$ UMl 113 & & & \\
\hline 9 & H9 & UMI $1205 \times$ × LPA-2-395 & & & \\
\hline 10 & $\mathrm{H} 10$ & UMI $1205 \times$ UMl 467 & & & \\
\hline 11 & $\mathrm{H} 11$ & DMR-QPM-01-06-02 × K-155 & & & \\
\hline 12 & $\mathrm{H} 12$ & DMR-QPM-03-72 × LPA-2-285 & & & \\
\hline
\end{tabular}

*significant at 5\%; ** significant at $1 \%$.
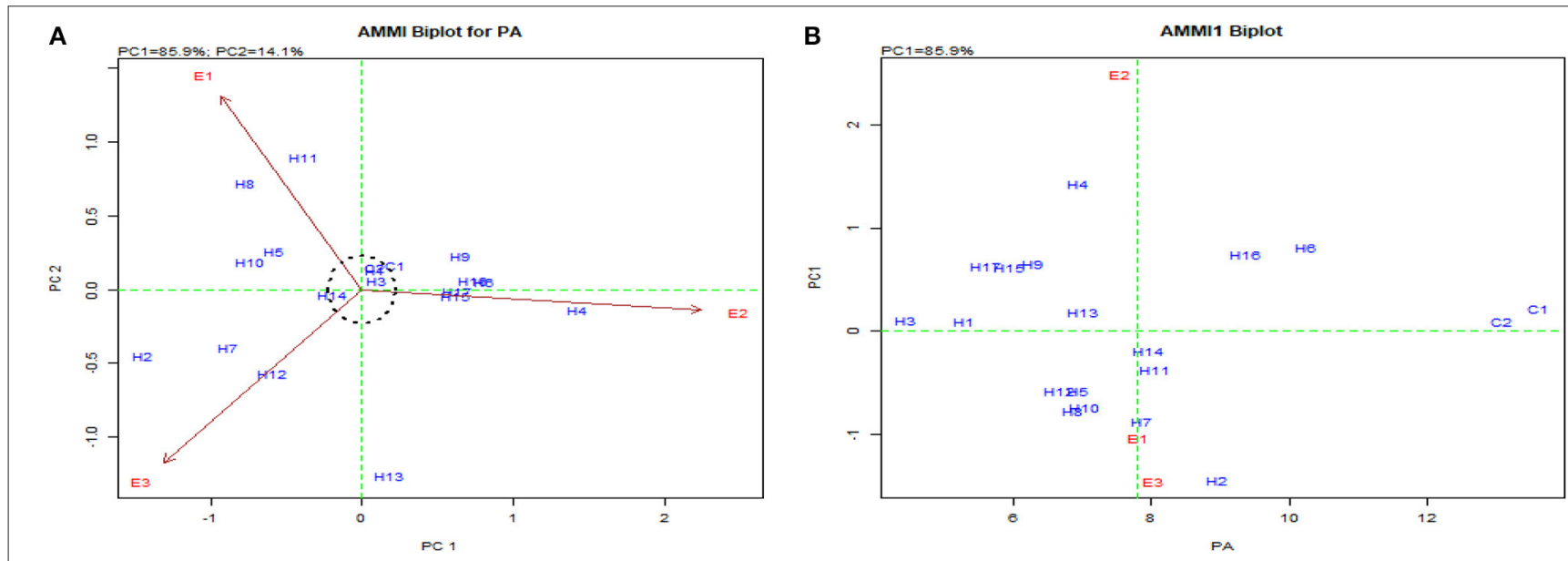

FIGURE 5 | AMMl biplot for PA in the hybrids. (A) AMMI biplot PC1 vs. PC2 for PA and (B) AMMl biplot for the mean of PA vs. PC1. 
LPA-2-285, and following this, UMI $1200 \times$ UMI 467, UMI $1200 \times$ LPA-2-285, DMR-QPM-04-05 $\times$ LPA-2-395, and DMRQPM-06-12 × UMI 447 had a lower per se cum sca for phytate. In $\mathrm{E}_{2}$ after UMI $1200 \times \mathrm{UMI} 467$, the hybrids UMI $1205 \times$ UMI 467, UMI $1201 \times$ UMI 113, DMR-QPM-03-72 × LPA-2285, and UMI $1200 \times$ UMI 447 were desirable for their lower mean and negative significant $s c a$. Moreover, at $\mathrm{E}_{3}$ with a minor difference in the order following UMI $1200 \times$ UMI 467, the hybrids UMI $1205 \times$ LPA-2-395, UMI $1200 \times$ UMI 158, UMI $1200 \times$ LPA-2-285, and DMR-QPM-11-17 $\times$ LPA-2-285 were lower in their mean with significant negative sca effects. Hence, the identified lpa hybrids from individual locations that were subjected in the stability models were DMR-QPM-11-17 $\times$ LPA2-285, UMI $1200 \times$ UMI 467, DMR-QPM-04-05 × LPA-2-395, DMR-QPM-06-12 × UMI 447, UMI $1205 \times$ UMI 467, UMI $1201 \times$ UMI 113, DMR-QPM-03-72 × LPA-2-285, UMI 1200 $\times$ UMI 447, UMI $1205 \times$ LPA-2-395, and UMI $1200 \times$ UMI 158 (Figure 4C). Considering all the three traits and the overall selection of hybrids based on their mean and sca for yield, PA and tryptophan presented a set of 17 hybrids and these were further subjected to a stability analysis in AMMI and GGE biplot (Tables 4, 5).

\section{Stability of the Desirable Hybrids With Ipa and Higher Yield by AMMI and GGE Biplot}

The pooled ANOVA for PA and yield revealed a significant $G \times$ $\mathrm{E}$ interaction for 72 hybrids raised in three locations (Table 4). The efficient graphical stability models such as AMMI and GGE biplot were performed for 17 desirable hybrids identified in individual locations for yield and $l_{p a}$ from the "Best performing single cross hybrids over locations" section to overcome the noise in graphs as reported by Gauch (1992) (Table 5). The AMMI biplot for PA had two principal components (PCs), with PC1 encountering a maximum $\mathrm{G} \times \mathrm{E}$ interaction of $85.90 \%$, followed by PC2 with $14.10 \%$. From AMMI, UMI $1200 \times$ UMI 467,
UMI $1200 \times$ LPA-2-285, CO 6, CO H(M) 8, and DMR-QPM06-12 $\times$ LPA-2-285 were stable for their PA with desirable PC scores falling inside the circle of origin (Figure 5A). Among these stable hybrids, UMI $1200 \times$ UMI 467 and UMI 1200 $\times$ LPA-2-285 had a lpa, while the rest of them were stable for their higher phytate ranges (Figure 5B). The hybrids that exactly fall on the origin of the circle possess a consistent performance for PA, and in this, UMI $1200 \times$ UMI 467 was found to be stable for lpa across locations (Yates and Cochran, 1938).

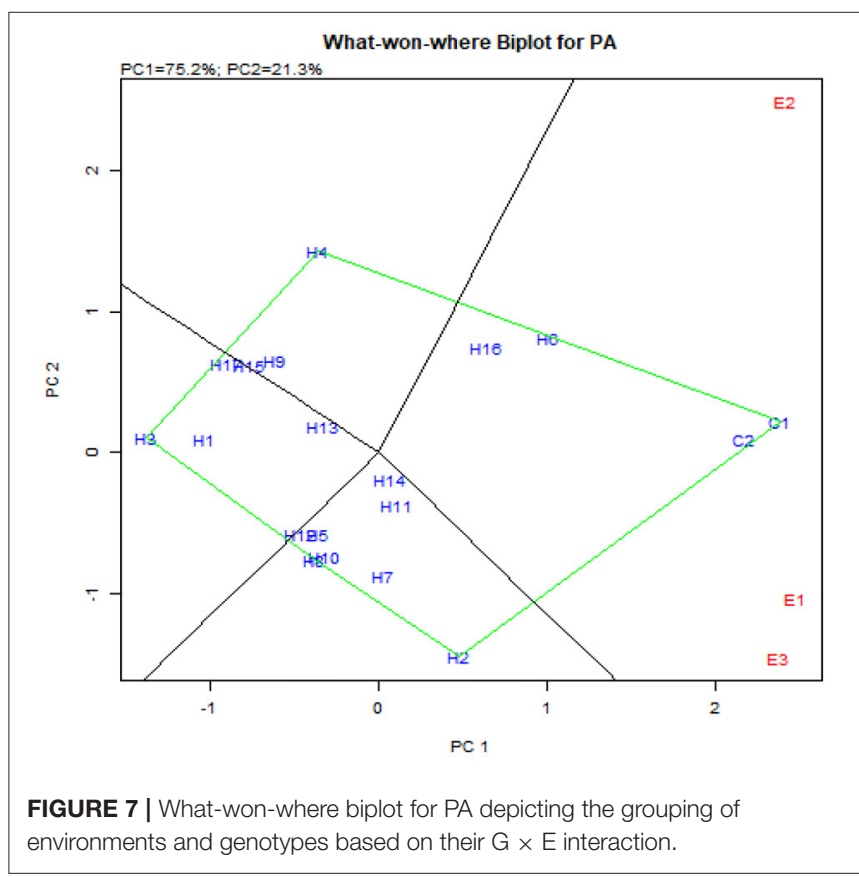

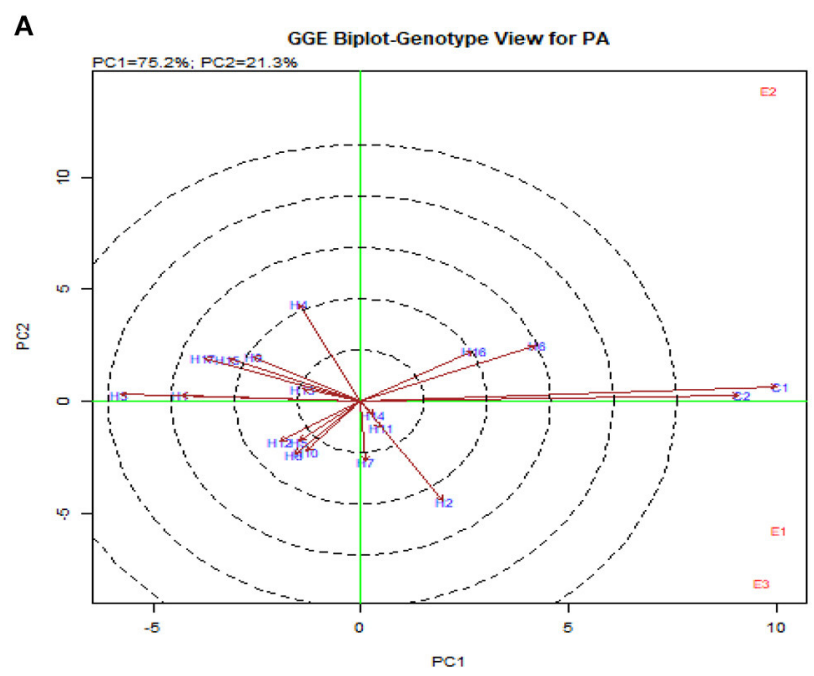

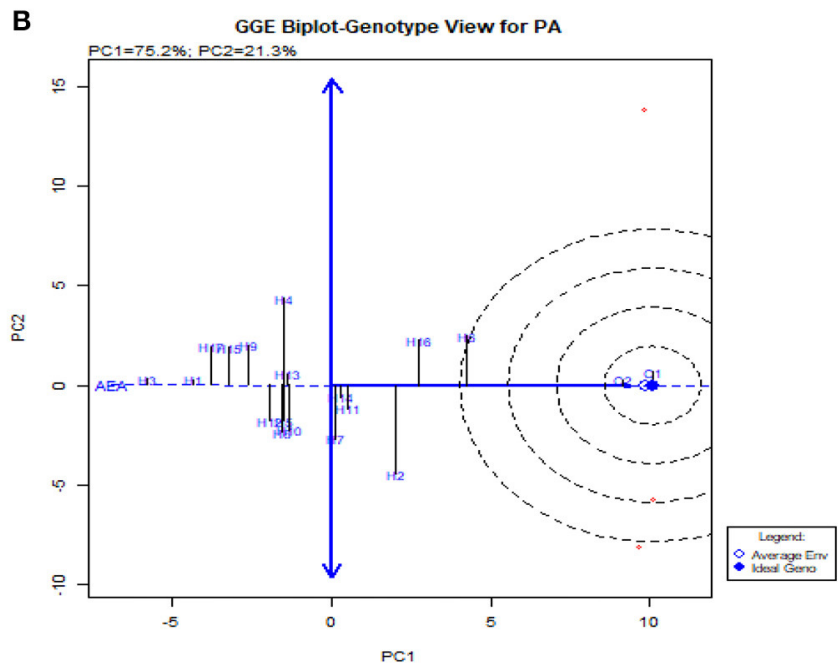

FIGURE 6 | GGE biplot for PA in hybrids. (A) The genotype view of the hybrids in the GGE plot. (B) The ideal genotype plot for hybrids in the GGE biplot. 
The GGE biplot was similar to AMMI with $75.20 \%$ in PC1 and $21.30 \%$ in $\mathrm{PC} 2$ for $\mathrm{G} \times \mathrm{E}$ interactions (Balestre et al., 2009). The genotype view of the GGE biplot exhibited the stable performance of UMI $1200 \times$ UMI 467 and UMI $1200 \times$ LPA-2285 with their arrows falling in the negative quadrant near the PC2 axis (Figure 6). The ideal genotype plot in GGE depicts the check CO 6 as ideal for its higher stable PA. For stable lpa, UMI $1200 \times$ UMI 467 that fell on a similar origin in the negative quadrant is ideal (Balestre et al., 2009). For PA in the what-wonwhere biplot, $\mathrm{E}_{1}$ and $\mathrm{E}_{3}$ (Figures 6,7 ) had a similar action toward the crosses raised, and this stated that any one of these locations could be omitted in other multilocational trials for studying the environmental variations in PA (Yates and Cochran, 1938).

The stability for the second response factor in AMMI biplot for yield presented the hybrids such as UMI $1205 \times$ UMI 467, UMI $1200 \times$ UMI 467, CO H(M) 8, CO 6, and DMR-QPM-04-05 $\times$ LPA-2-395 as stable. They were found near the origin within the concentric circle (Balestre et al., 2009). Although these hybrids were stable, the highest stable performance for yield was exhibited by the checks $\mathrm{CO} 6$ and $\mathrm{CO} \mathrm{H}(\mathrm{M}) 8$, which were released hybrids (Nallathambi et al., 2012). The potent yielder, DMR-QPM-09-13-1 × UMI 1099, had stable
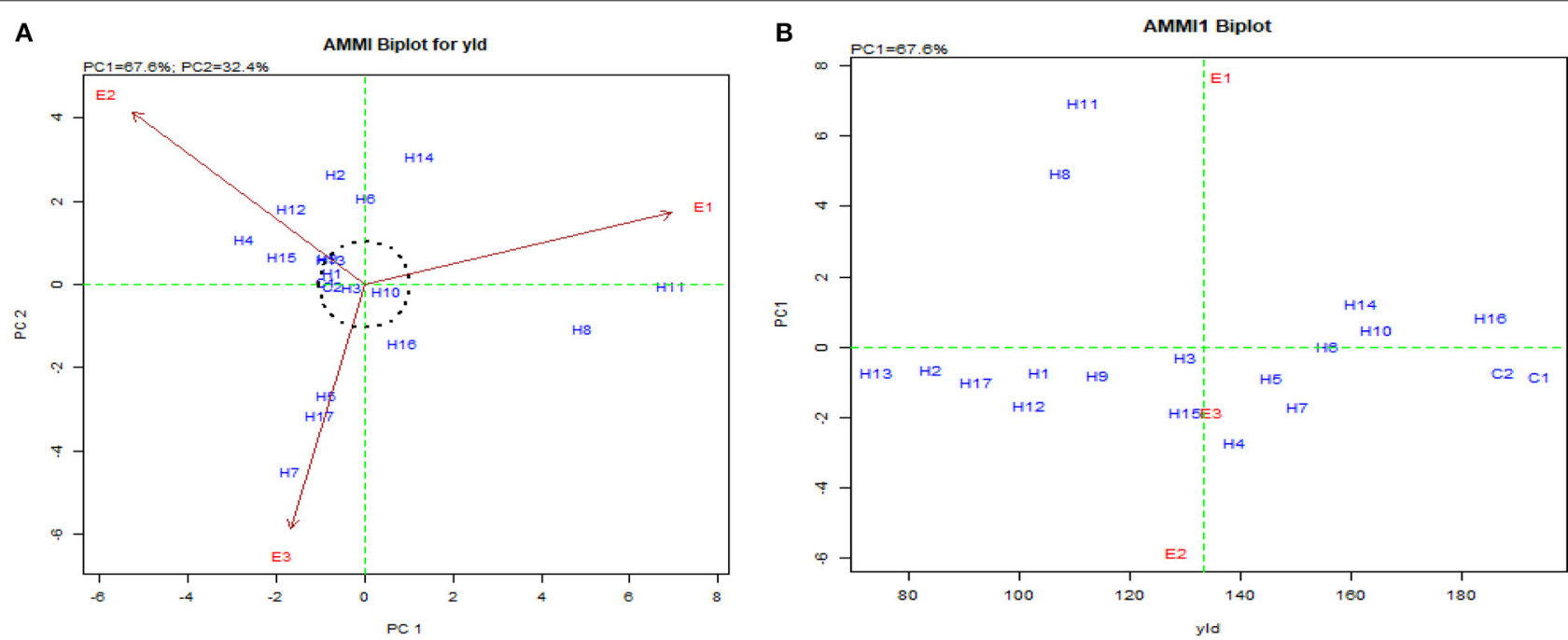

FIGURE 8 | AMMI biplot for single plant yield in the hybrids. (A) AMMI biplot PC1 vs. PC2 for single plant yield and (B) AMMI biplot for the mean of single plant yield (yld) vs. PC1.
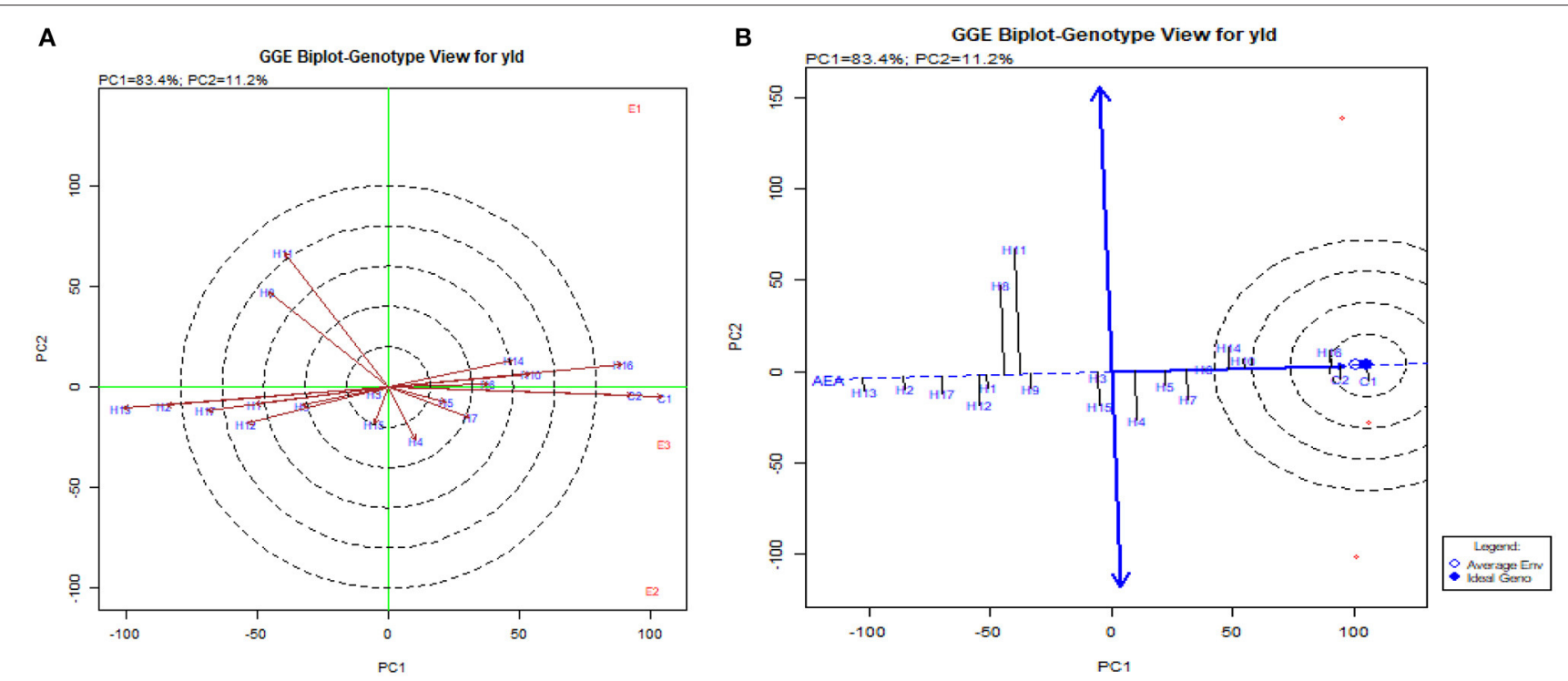

FIGURE 9 | GGE biplot for single plant yield in hybrids. (A) The genotype view of the hybrids for single plant yield in the GGE plot. (B) The ideal genotype plot of hybrids for single plant yield in the GGE biplot. 
performances in $E_{1}$ and $E_{3}$, but due to the prevailing rainfed situations in $\mathrm{E}_{2}$, a reduction in yield was observed (Pramitha et al., 2020). From the overall mean and PC performance in AMMI for yield (Figure 8A), DMR-QPM-09-13-1 × UMI 1099 with the highest mean and a higher PC1 in the positive quadrant near the $\mathrm{x}$-axis could be identified as an elite stable hybrid (Figure 8B).

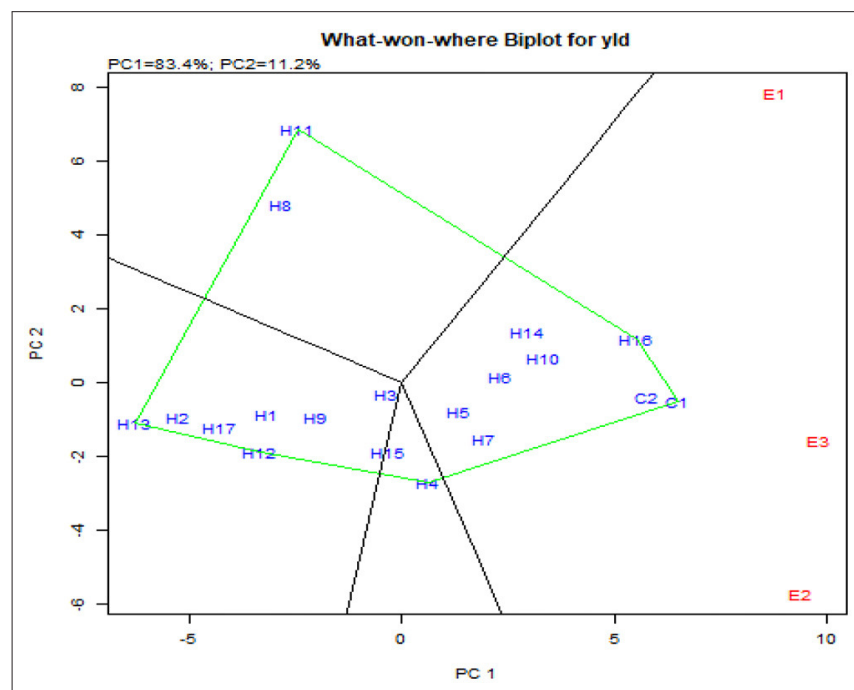

FIGURE 10 | What-won-where biplot for single plant yield depicting the grouping of environments and genotypes based on their $\mathrm{G} \times \mathrm{E}$ interaction.
Concomitantly, the GGE biplot also had similar results with $\mathrm{CO}$ 6, CO H(M) 8, DMR-QPM-09-13-1 × UMI 1099, and UMI $1205 \times$ UMI 467 as stable high-yielding genotypes in the positive quadrant of the $\mathrm{x}$-axis (Figure $\mathbf{9 A}$ ). Also, as a confirmation for ideal hybrid in the GGE biplot, CO 6, $\mathrm{CO} \mathrm{H}(\mathrm{M})$ 8, and DMR-QPM-09-13-1 × UMI 1099 were falling near the origin of the ideal axis (Akhtar et al., 2018). All the environments in the what-won-where plot for yield had a differential interaction toward the hybrids, and this states that other multilocational trials for yield could be conducted in larger plots across these places in the future (Figures 9, 10).

\section{Selection of Desirable Hybrids for Evaluation}

All the hybrids obtained had a higher tryptophan and lower PA than the checks. Although the hybrids were superior to the checks in terms of nutritional quality, none of them were found to surpass the checks for yield and starch (Supplementary Tables 8-23). These effects in the overall reduction for yield and starch were due to the significant positive correlation of yield with PA and starch (Pramitha et al., 2019). Since PA is involved in the myoinositol pathway that includes starch synthesis, its reduction has effected altered grain starch content in hybrids. These pleiotropic effects of PA on yield attributing traits were coherently reported by Brankovic et al.

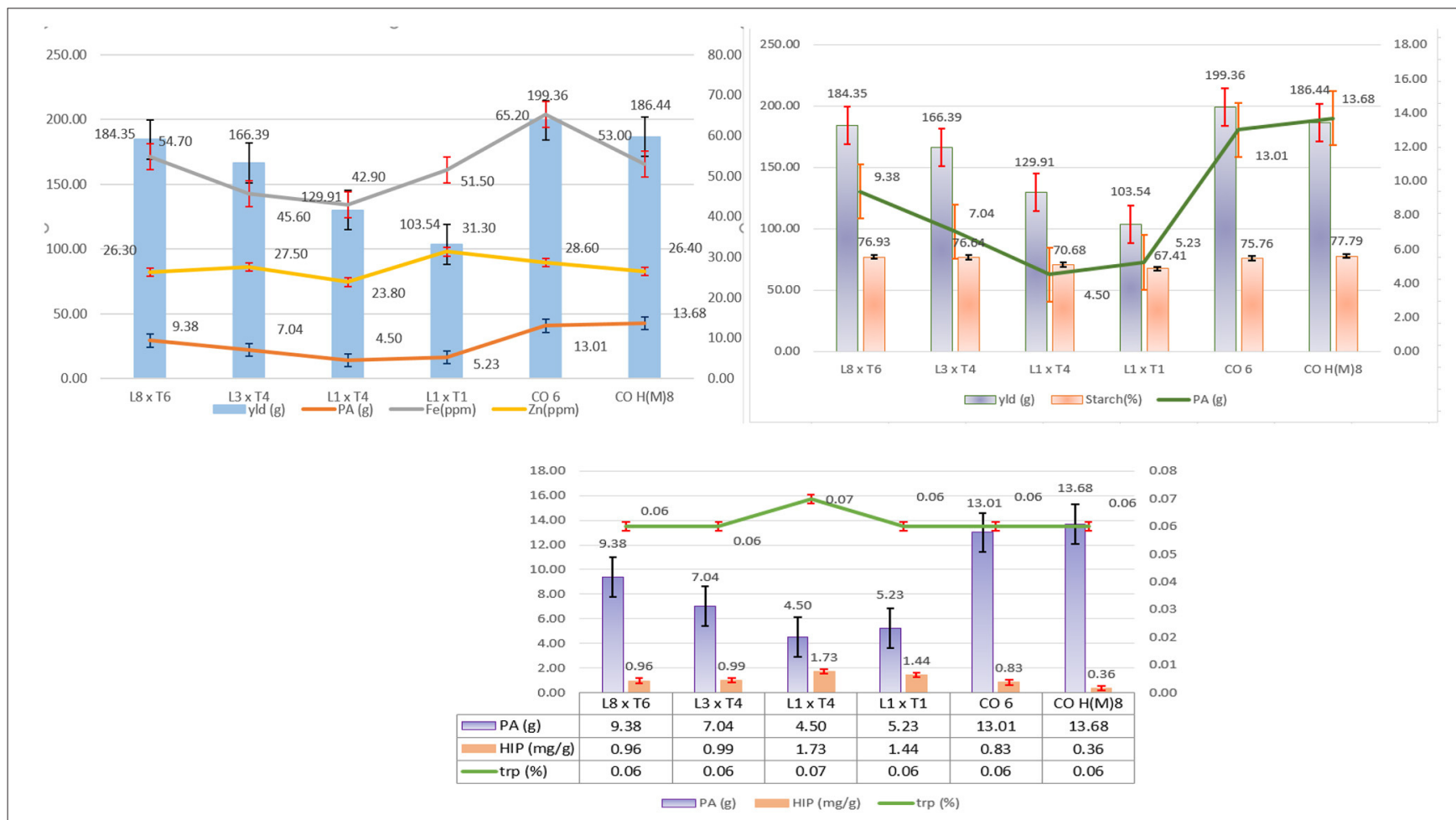

FIGURE 11 | The overall performance of the selected and identified hybrids with standard checks $\mathrm{CO} 6$ and $\mathrm{CO} H(\mathrm{M}) 8$ for single plant yield ( $\mathrm{g})$, PA (mg/g), iron (ppm), zinc (ppm) starch (\%), HIP (mg/g), and tryptophan (\%). Comparative performances of yield with PA, HIP, tryptophan, iron zinc, and starch are depicted. 
TABLE 6 | General and specific combining ability of parents and hybrids for PA across locations.

\begin{tabular}{|c|c|c|c|c|c|c|c|c|c|}
\hline \multicolumn{10}{|l|}{ Phytic acid } \\
\hline L2 & $4.36^{\star \star}$ & $2.38^{\star \star}$ & $-0.53^{\star}$ & $-0.79^{* \star}$ & 0.14 & $-2.27^{\star \star}$ & $0.86^{\star \star}$ & $-4.14^{\star \star}$ & 0.00 \\
\hline L3 & $-0.69^{\star *}$ & $0.86^{\star \star}$ & $0.80^{\star \star}$ & $-3.09^{\star \star}$ & $-1.31^{\star \star}$ & $-0.88^{\star \star}$ & $0.62^{\star}$ & $3.69^{\star \star}$ & $-0.27^{\star \star}$ \\
\hline L4 & $-1.72^{\star *}$ & $-1.25^{\star \star}$ & 0.21 & $4.69^{\star \star}$ & $-1.61^{\star \star}$ & $1.56^{\star \star}$ & $-1.00^{\star \star}$ & $-0.88^{\star \star}$ & 0.06 \\
\hline L6 & $2.83^{* \star}$ & -0.03 & -0.18 & -0.26 & 0.44 & $0.62^{\star}$ & $-1.95^{\star \star}$ & $-1.48^{\star \star}$ & $0.39^{\star \star}$ \\
\hline L7 & $-0.97^{\star \star}$ & $-2.06^{\star \star}$ & -0.27 & $1.07^{\star \star}$ & $1.73^{\star \star}$ & $-1.51^{\star \star}$ & $3.86^{\star \star}$ & $-1.85^{\star \star}$ & $0.57^{\star \star}$ \\
\hline L8 & 0.26 & -0.29 & $1.05^{\star \star}$ & 0.45 & $-1.85^{\star \star}$ & $2.30^{\star \star}$ & $-1.36^{\star \star}$ & $-0.55^{*}$ & $0.90^{\star \star}$ \\
\hline L9 & $-0.79^{\star \star}$ & $-1.51^{\star \star}$ & $0.59^{*}$ & $-0.56^{\star}$ & -0.25 & $-0.60^{*}$ & $0.64^{*}$ & $2.47^{\star \star}$ & 0.08 \\
\hline Testers & $-0.22^{\star \star}$ & $-0.82^{\star \star}$ & $-0.93^{\star \star}$ & $0.40^{\star \star}$ & $1.05^{\star \star}$ & -0.12 & $-0.22^{\star \star}$ & $0.85^{\star \star}$ & \\
\hline
\end{tabular}

${ }^{*}$ Significant at 5\%; * significant at 1\%.

TABLE 7 | The grouping of the lines in the tester groups based on their combining ability.

\begin{tabular}{|c|c|c|c|c|}
\hline $\begin{array}{l}\text { Heterotic group-I } \\
\text { UMI } 158 \text { \& UMI } 447 \text { Pool I }\end{array}$ & & \multicolumn{3}{|l|}{ Heterotic group-II } \\
\hline DMR-QPM-09-13-1 & UMI 1200 & UMI 1200 & DMR-QPM-01-06-02 & UMI 1201 \\
\hline DMR-QPM-11-17 & UMI 1201 & UMI 1205 & DMR-QPM-06-12 & DMR-QPM-04-05 \\
\hline UMI 1205 & DMR-QPM-03-72 & DMR-QPM-11-17 & DMR-QPM-09-13-1 & \\
\hline & DMR-QPM-06-12 & & & \\
\hline
\end{tabular}

(2016) in wheat. Consequently, across locations, all the hybrids exhibited a significant $G \times E$ interaction for $P A$ and yield (Balestre et al., 2009).

In addition to this, as the attributing traits were varying across locations, the tryptophan in hybrids also varied, whereas they were higher than the checks that were used. Hence, to identify a desirable hybrid with lpa and tryptophan, the preliminary selection indices were focused initially on dissecting a stable hybrid with lpa and yield.

From these selected stable hybrids from AMMI and GGE biplots, the higher tryptophan hybrids were then scrutinized to identify a desirable genotype with all three response factors. This variation of tryptophan across locations was also reported by Zaidi et al. (2008), and the top-performing hybrids for tryptophan from individual locations in the "Best performing single cross hybrids over locations" section have to be evaluated simultaneously in the future to identify the attributing traits for its stability.

Among the 72 hybrids raised in locations, four of them, namely, DMR-QPM-09-13-1 × UMI 1099, UMI $1205 \times$ UMI 467, UMI $1200 \times$ UMI 467, and UMI $1200 \times$ LPA-2-285, were stable in AMMI and GGE biplots for their yield and PA with a higher tryptophan content (Figure 11) (Yates and Cochran, 1938). The buffering in yield among all hybrids was noticed due to the highest interaction of $\mathrm{E}_{2}$ (Oomah et al., 1996; Kayodé Polycarpe et al., 2006; Balestre et al., 2009). Even the highest yielder DMR-QPM-09-13-1 × UMI 1099 had a reduction in its yield due to the prevailing rainfed situations in $\mathrm{E}_{2}$ (Zaidi et al., 2008; Brankovic et al., 2016). The PA in crops is known to regulate anthesis, pollination, seedling vigor, starch accumulation, and stress tolerance in plants (Pramitha et al., 2021). Thus, its reduction by $l p a$ donors has caused the average performance of hybrids as compared to the checks across locations. Thereby, the compensation of these negative pleiotropic effects such as reduced starch, cob girth, and single plant yield from the lpa donors has to be reinforced in upcoming biofortification trials of maize (Bregitzer et al., 2008; Lorenz et al., 2008).

From the superior hybrids, the highest yielder DMR-QPM09-13-1 × UMI 1099 consisted of parents in a combination of low $g c a \times$ high $g c a$ effect (Supplementary Tables 8-23). This explains that the heterotic expression has been resulted by combined additive effects of favorable alleles in UMI 1099 and an epistatic effect of desirable alleles in DMR-QPM-09-131 (Fasahat, 2016). Similar heterotic combinations of parents with varying gca effects were observed in UMI $1200 \times$ UMI 467 and UMI $1200 \times$ LPA-2-285. Such kinds of heterotic effects were also reported by Sun et al. (2018). The second highest yield performer, UMI $1205 \times$ UMI 467, had a good favorable gca 
combination, comprising two good gca parents in its cross. This is in accordance with several findings, including Uddin et al. (2006) and Kumar et al. (2016), and the higher yield is ascribed due to the additive gene action of the favorable alleles from both parents.

The most successful hybrid attained from these crosses with lpa and higher tryptophan was UMI $1200 \times$ UMI 467. Among all the hybrids, this had the lowest PA $(4.92 \mathrm{mg} / \mathrm{g})$ and the highest tryptophan content $(0.07 \%)$ with a stable yield $(129.91 \mathrm{~g})$ across locations. Hence, this study confirms the simultaneous improvisation of PA and tryptophan in maize. Thus, the parental inbreds used here were grouped into heterotic groups for further use as a reference in breeding programs.

\section{Analyzing Nutritional Parameters of the Selected Hybrids}

Among all the screened hybrids, UMI $1200 \times$ UMI 467 followed by UMI $1200 \times$ LPA-2-285 had the lowest PA with HIP, moderate starch, and tryptophan across locations. Among these two, UMI $1200 \times$ UMI 467 had a uniform yield, lpa, and highest tryptophan. Reinforcing yield for commercialization, the hybrid DMR-QPM-09-13-1 × UMI 1099 followed by UMI $1205 \times$ UMI 467 had the highest stable yield with medium PA and tryptophan. These high yielders with moderate lpa also had a higher starch content than the rest of them. To conclude, all the four hybrids, namely, DMR-QPM-09-13-1 $\times$ UMI 1099, UMI $1205 \times$ UMI 467, UMI $1200 \times$ UMI 467, and UMI $1200 \times$ LPA-2-285 identified from this study also had a higher $\mathrm{Fe}$ and $\mathrm{Zn}$ than the checks (Figure 11). Hence, these hybrids could be forwarded in other trials for analyzing their elite performance and PA: mineral ratio to afford an enhanced bioavailability of minerals in maize diets (Hambidge et al., 2005).

\section{Heterotic Grouping of Parental Inbreds}

The heterotic grouping of inbreds for PA facilitates maintaining the parental inbreds in their designated pools to recreate varying combinations for $\mathrm{PA}$ in near future. This reduces the necessity of analyzing their combining ability performances repeatedly. In this study, the method that relies on the combining ability adopted by Legesse et al. (2009) was followed. Based on this, two testers with diverse gca effects for PA have been selected (Table 5). The testers for the first group were UMI 447 and UMI 158, while those for the second group were UMI 467 and UMI 113. These testers had extreme negative and positive significant $g c a$ for phytate across locations. The lines that exhibit a significant negative sca with one of the testers are grouped with the tester with whom it established a negative sca. Those that show a negative sca with both of them fall under the combined group of both testers and vice versa are rejected (Table 6). This favors varying lines with the testers for producing a lower PA content in the hybrids.
By adopting this method, two groups, namely, 1. UMI 447 and UMI 158 and 2. UMI 467 and UMI 113, were formed. The sum of the sca and the mean values for all the crosses in each group were estimated separately, and this revealed UMI 447 and UMI 158 as a desirable pool incorporating a lower mean and negative sca for all line $\times$ tester phytate combinations (Table 7). Hence, this group could be identified as a favorable heterotic pool for preserving the parental inbreds for lpa. This could be further elaborated by including more stable lpa inbreds and combiners in the future.

\section{CONCLUSION}

The study focuses on simultaneous improvisation with reduced PA and increased tryptophan content in maize grain. The identified hybrids were found nutritionally superior with a compromise in their yield as compared to the check hybrids. Hence, introgressing elite parents such as UMI 1205 and UMI 1201 with lpa and higher tryptophan will lead to developing superior parents with desirable traits for crossing. Furthermore, implying these Near Isogenic Line (NILs) in the production of hybrids would be rewarding to overcome the yield constraints in commercialization. Also, as drastic reductions in phytate were found to alter the yield, these high-yielding moderate phytate and tryptophan hybrids, such as DMR-QPM-09-13-1 × UMI 1099 and UMI $1205 \times$ UMI 467, could be evaluated for their efficiency in nutrient uptake by analyzing their mineral ratios in feeds. Therefore, this heterotic pool along with identified hybrids could be maintained as a reference population in the biofortification of maize, and it could help in framing the phases for producing elite lpa cum tryptophan hybrids in the future.

\section{DATA AVAILABILITY STATEMENT}

The original contributions presented in the study are included in the article/Supplementary Material, further inquiries can be directed to the corresponding author.

\section{AUTHOR CONTRIBUTIONS}

All authors listed have made a substantial, direct, and intellectual contribution to the work and approved it for publication.

\section{SUPPLEMENTARY MATERIAL}

The Supplementary Material for this article can be found online at: https://www.frontiersin.org/articles/10.3389/fpls.2021. 781469/full\#supplementary-material 


\section{REFERENCES}

Abdul-Baki, A. A., and Anderson, J. D. (1973). Vigor determination in soybean seed by multiple criteria 1. Crop Sci. 13, 630-633. doi: 10.2135/cropsci1973.0011183X001300 060013x

Akhtar, S., Osthoff, G., Mashingaidze, K., and Labuschagne, M. (2018). Iron and zinc in maize in the developing world: deficiency, availability, and breeding. Crop Sci. 58, 2200-2213. doi: 10.2135/cropsci2018. 02.0133

Al-Naggar, A., Atta, M., Ahmed, M., and Younis, A. (2016). Heterosis and combining ability of maize (Zea mays L.) grain protein, oil and starch content and yield as affected by water stress. Archiv. Curr. Res. Int. 4, 1-15. doi: 10.9734/ACRI/2016/ 27508

Balestre, M., Von Pinho, R. G., Souza, J. C., and Oliveira, R. L. (2009). Genotypic stability and adaptability in tropical maize based on AMMI and GGE biplot analysis. Genet. Mol. Res. 8, 1311-1322. doi: 10.4238/vol8-4gmr658

Brankovic, G., Dragicevic, V., Zilic, S., Knezevic, D., Djuric, N., and Dodig, D. (2016). Expected genetic advance and stability of phytic acid and antioxidants content in bread and durum wheat. Genetika 48, 867-880. doi: 10.2298/GENSR1603867B

Bregitzer, P., Dahleen, L. S., Neate, S., Schwarz, P., and Manoharan, M. (2008). A single backcross effectively eliminates agronomic and quality alterations caused by somaclonal variation in transgenic barley. Crop Sci. 48, 4 71-479. doi: 10.2135/cropsci2007.06.0370

Chandana, A. S., John Joel, A., Ravikesavan R., and Uma, D. (2018). Genetic variability and correlation studies of yield and phytic acid in F2 populations of maize (Zea mays L.). Electron. J. Plant Breed. 9, 1469-1475. doi: 10.5958/0975-928X.2018.00182.5

Clegg, K. M. (1956). The application of the anthrone reagent to the estimation of starch in cereals. J. Food Sci 7, 40-44. doi: 10.1002/jsfa.2740070108

Davies, N. T., and Reid, H. (1979). An evaluation of the phytate, zinc, copper, iron and manganese contents of, and $\mathrm{Zn}$ availability from, soya-based texturedvegetable-protein meat-substitutes or meat-extenders. Br. J. Nutri. 41, 579-589. doi: 10.1079/BJN19790073

Farnham, D. E., Benson, G. O., and Pearce, R. B. (2003). Corn Perspective and Culture. Corn: chemistry and technology. Available online at: https://www. cabdirect.org/cabdirect/abstract/20033163519.

Fasahat, P. (2016). Principles and utilization of combining ability in plant breeding. Biometrics Biostat. Int. J. 4, 1-22. doi: 10.15406/bbij.2016.04.00085

Ferreira, L. U., Melo, P. G. S., Vieira, R. F., Lobo Junior, M., Pereira, H. S., Melo, L. C., et al. (2018). Combining ability as a strategy for selecting common bean parents and populations resistant to white mold. Crop Breed. Appl. Biotechnol. 18, 276-283. doi: 10.1590/1984-70332018v18n3a41

Galicia, L. N., Rosales, E., and and, A., Palacios Rojas, N. (2009). "Maize nutrition quality and plant tissue analysis laboratory," In Laboratory Protocols (p. CIMMYT).

Gauch, H. G. (1992). Statistical Analysis of Regional Yield Trials:AMMI Analysis of Factorial Designs. Amsterdam: Elsevier.

Hambidge, K. M., Krebs, N. F., Westcott, J. L., Sian, L., Miller, L. V., Peterson, K. L., et al. (2005). Absorption of calcium from tortilla meals prepared from low-phytate maize-. The Am. J. Clinic. Nutri. 82, 84-87. doi: 10.1093/ajcn/8 2.1.84

Ignjatovic-Micic, D., Kostadinovic, M., Bozinovic, S., Andjelkovic, V., and Vancetovic, J. (2014). High grain quality accessions within a maize drought tolerant core collection. Scientia Agricola 71, 402-409. doi: 10.1590/0103-9016-2013-0112

Kayodé Polycarpe, A. P., Linnemann, A. R., Hounhouigan, J. D., Nout, M. J. R., and Van Boekel, M. A. J. S. (2006). Genetic and environmental impact on iron, zinc, and phytate in food sorghum grown in Benin. J. Agricult. Food Chemistr. 54, 256-262. doi: 10.1021/jf0521404

Kempthorne, O. (1957). An Introduction to Genetic Statistics. New York, NY: Wiley Kumar, M., Verma, S. S., Uniyal, M., Barh, A., and Singh, N. K. (2016). Exploitation of combining ability and heterosis for development of maize hybrids for tarai region of Uttarakhand. J. Appl. Nat. Sci. 8, 1570-1575. doi: 10.31018 /jans.v8i3.1002
Kuselan, K. (2017). Combining ability of maize inbreds for yield and component traits in multi environment diallel analysis. Int. J. pure app. biosci 50, 725-729. doi: 10.18782/2320-7051.5238

Lahane, G. R., Chauhan, R. M., and Lahane, J. M. P. (2014). Combining ability and heterosis for yield and quality traits in quality protein maize. $J$. AgriSearch 3, 135-138. Available online at: https://jsure.org.in/journal/index. php/jas/article/view/39/45

Legesse, B. W., Pixley, K. V., and Botha, A. M. (2009). Combining ability and heterotic grouping of highland transition maize inbred lines. Maydica 54, 1-9.

Lelis, G. R., Albino, L. F. T., Calderano, A. A., Tavernari, F., de, C., Rostagno, H. S., et al. (2012). Diet supplementation with phytase on performance of broiler chickens. Revista Brasileira de Zootecnia 41, 929-933. doi: 10.1590/S1516-35982012000400014

Lorenz, A. J., Scott, M. P., and Lamkey, K. R. (2008). Genetic variation and breeding potential of phytate and inorganic phosphorus in a maize population. Crop Sci. 48, 79-84. doi: 10.2135/cropsci2007.03.0136

Malik, S. I., Malik, H. N., Minhas, N. M., and Munir, M. U. H. A. M. M. A. D. (2004). General and specific combining ability studies in maize diallel crosses. Int. J. Agri. Biol. 6, 856-859.

Meredith, W. R., and Bridge, R. R. (1972). Heterosis and Gene Action in Cotton, Gossypium hirsutum L. Crop Sci. 12, 304-310. doi: 10.2135/cropsci1972.0011183X001200030015x

Mural, R. V. (2012). Combining ability analysis in quality protein maize (Zea mays L.) for grain yield and its component traits. Electron. J. Plant Breed. 2, 747-752.

Murtadha, M. A., Ariyo, O. J., and Alghamdi, S. S. (2018). Analysis of combining ability over environments in diallel crosses of maize (Zea mays). J. Saudi Society Agric. Sci. 17, 69-78. doi: 10.1016/j.jssas.2016.01.004

Naidoo, R., Tongoona, P., Derera, J., Laing, M. D., and Watson, G. M. F. (2012). Combining ability of low phytic acid (lpa1-1) and quality protein maize (QPM) lines for seed germination and vigour under stress and non-stress conditions. Euphytica 185, 529-541. doi: 10.1007/s10681-012-0677-1

Nallathambi, G., Ganesan, K. N., Tamilarasi, P. M., Sain, D ass., Thiyagarajan, K., Veerabadhiran, P., et al. (2012). A high yielding multiple disease resistant TNAU maize hybrid Co 6 for Tamil Nadu. Madras Agricult. J. 99, 677-680.

Oomah, B. D., Kenaschuk, E. O., and Mazza, G. (1996). Phytic acid content of flaxseed as influenced by cultivar, growing season, and location. J. Agricult. Food Chemistr. 44, 2 663-2666. doi: 10.1021/jf9601527

Palmer, R. A., and Piper, T. S. (1966). 2, 2'-Bipyridine Complexes. I. Polarized Crystal Spectra of Tris (2, 2'-bipyridine) copper (II), -nickel (II), -cobalt (II), -iron (II), and -ruthenium (II). Inorg. Chem. 5, 864-878. doi: 10.1021/ic50039a034

Pramitha, J. L., Jeeva, G., Joel, A. J., Ravikesavan, R., and Hossain, F. (2019). Association of phytic acid towards the yield attributing traits in maize (Zea Mays. L. Electron. J. Plant Breed.) 10, 1019-1029. doi: 10.5958/0975-928X.2019.00131.5

Pramitha, J. L., Jeeva, G., Ravikesavan, R., Joel, A. J., Vinothana, N. K., Meenakumari, B., et al. (2020b). Environmental impact of phytic acid in Maize (Zea mays. L) genotypes for the identification of stable inbreds for low phytic acid. Physiol. Mol. Biol. Plants 26, 1477-1488. doi: 10.1007/s12298-020-00818-x

Pramitha, J. L., Joel, A. J., Srinivas, S., Sreeja, R., Hossain, F., and Ravikesavan, R. (2020a). Enumerating the phytic acid content in maize germplasm and formulation of reference set to enhance the breeding for low phytic acid. Physiol. Mol. Biol. Plants 26, 353-365. doi: 10.1007/s12298-019-00725-w

Pramitha, J. L., Rana, S., Aggarwal, P. R., Ravikesavan, R., Joel, A. J., and Muthamilarasan, M. (2021). Diverse role of phytic acid in plants and approaches to develop low-phytate grains to enhance bioavailability of micronutrients. Adv. Genet 107, 89-120. doi: 10.1016/bs.adgen.2020.11.003

Raboy, V. (2000). Low-phytic-acid grains. Food Nutri. Bull. 21, 423-427. doi: 10.1177/156482650002100416

Raboy, V., Young, K. A., Dorsch, J. A., and Cook, A. (2001). Genetics and breeding of seed phosphorus and phytic acid. J. Plant Physiol. 158, 489-497. doi: 10.1078/0176-1617-00361

Shah Rouf, T., Prasad, K., and Kumar, P. (2016). Maize, A potential source of human nutrition and health: a review. Cogent Food Agricult. 2:15. doi: $10.1080 / 23311932.2016 .1166995$

Shull, G. H. (1909). A pure-line method in corn breeding. J. Heredity 1, 51-58. doi: 10.1093/jhered/os-5.1.51 
Sparvoli, F., and Eleonora, C. (2015). Seed biofortification and phytic acid reduction: a conflict of interest for the plant? Plants 4, 728-755. doi: 10.3390/plants4040728

Sun, J., Gao, J., Su, Z., Feng, Y., and Wang, D. (2018). Combining Ability of Sixteen U. S. A. Maize Inbred Lines and Utilization Potential as Hybrids in P. R. C. November 18:391. doi: 10.20944/preprints201811.0391.v1

Sureshkumar, S., Tamilkumar, P., Thangavelu, A. U., Senthil, N., Nagarajan, P., Vellaikumar, S., et al. (2014). Marker-assisted introgression of lpa2 locus responsible for low-phytic acid trait into an elite tropical maize inbred (Zea mays L.). Plant Breed. 133, 566-578. doi: 10.1111/pbr. 12185

Uddin, M. S., Khatun, F., Ahmed, S., Ali, M. R., and Bagum, S. A. (2006). Heterosis and combining ability in corn (Zea mays L.). Bangl. J. Bot. 35, 109-116.

Vaezi, B., Pour-Aboughadareh, A., Mohammadi, R., Mehraban, A., Hossein-Pour, T., Koohkan, E., et al. (2019). Integrating different stability models to investigate genotypex environment interactions and identify stable and high-yielding barley genotypes. Euphytica 215, 1-18. doi: $10.1007 /$ s10681-019-2386-5

Vasal, S. K. (2000). The quality protein maize story. Food Nutr. Bull. 21, 445-450. doi: $10.1177 / 156482650002100420$

Vengilat, V. P., Joel, A. J., Lydia Pramitha, J., and Ravikesavan, R. (2019). Studies on correlation of the seed speherecity and seedling characteristics of Studies on correlation of the seed speherecity and seedling characteristics of maize (Zea mays L.) inbred lines. J. Pharmacogn. Phytochemistr. 8, 3434-3437.
Yates, F., and Cochran, W. G. (1938). The analysis of groups of experiments. J. Agricult. Sci. 28, 556-580. doi: 10.1017/S0021859600050978

Zaidi, P. H., Vasal, S. K., Maniselvan, P., Jha, G. C., Mehrajjudin, and Singh, R. P. (2008). Stability in performance of quality protein maize under abiotic stress. Maydica. 53,249-260.

Conflict of Interest: The authors declare that the research was conducted in the absence of any commercial or financial relationships that could be construed as a potential conflict of interest.

Publisher's Note: All claims expressed in this article are solely those of the authors and do not necessarily represent those of their affiliated organizations, or those of the publisher, the editors and the reviewers. Any product that may be evaluated in this article, or claim that may be made by its manufacturer, is not guaranteed or endorsed by the publisher.

Copyright (c) 2022 Lydia Pramitha, Joel, Rajasekaran, Uma, Vinothana, Balakrishnan, Sathyasheela, Muthurajan and Hossain. This is an open-access article distributed under the terms of the Creative Commons Attribution License (CC BY). The use, distribution or reproduction in other forums is permitted, provided the original author(s) and the copyright owner(s) are credited and that the original publication in this journal is cited, in accordance with accepted academic practice. No use, distribution or reproduction is permitted which does not comply with these terms. 